\title{
Antrenörlük ve Öğretmenlik Bölümü Öğrencilerinin Akademik İyimserlik ve Psikolojik İyi Oluş Düzeylerinin İncelenmesi ${ }^{1}$
}

\author{
Tamer KARADEMIR \\ Doç. Dr., Kahramanmaraş Sütçü İmam Üniversitesi, \\ Beden Eğitimi ve Spor Yüksekokulu \\ tamer.karademir@hotmail.com \\ Orcid ID: https://orcid.org/0000-0003-3244-0767 \\ Mahmut AÇAK \\ Doç. Dr., İnönü Üniversitesi, Spor Bilimleri Fakültesi \\ m.acak@hotmail.com \\ Orcid ID: https://orcid.org/0000-0002-2843-4834
}

\begin{abstract}
Öz
$\mathrm{Bu}$ çalışma beden eğitim ve spor öğretmenliği ile antrenörlük eğitimi bölümlerinde okuyan öğrencilerin akademik iyimserlik ve psikolojik iyi oluş düzeylerinin bazı değişkenlere göre nasıl şekillendiğini belirlemek amacı ile yapılmıştır. Araştırmaya gönüllü olarak katılmak isteyen beden eğitimi ve spor öğretmenliği bölümünden 160, antrenörlük eğitimi bölümünden 120 olmak üzere toplam 280 öğrenci dahil edilmiştir. Araştırmanın çalışma evreni 385 öğrencidir. Araştırma verileri 2017-2018 akademik yılında kişisel bilgi formunun yanı sıra akademik iyimserlik ve psikolojik iyi oluş ölçekleri kullanılarak toplanmıştır. Araştırma sonuçlarına göre; çalışma grubunun cinsiyet değişkenine göre bayan ve erkek öğrencilerin akademik iyimserlik ve psikolojik iyi oluş düzeylerine ait puan ortalamaları arasında benzerlik olduğu görülmüştür. Beden eğitimi öğretmenliği bölümü öğrencilerinin antrenörlük eğitimi bölümü öğrencilerine göre, özel yurtta kalanların devlet yurdunda kalanlara göre psikolojik iyi oluş düzeylerinin daha yüksek $(X=120,32)$ olduğu belirlenmiştir.
\end{abstract}

Anahtar Kelimeler: Akademik İyimserlik, Psikolojik İyi Oluş, Spor, Eğitim.

\footnotetext{
${ }^{1}$ Makale Geliş/Kabul Tarihi: 16.05.2019 / 26.07.2019

Künye Bilgisi: Karademir, T. ve Açak, M. (2020). Antrenörlük ve Öğretmenlik Bölümü Ögrencilerinin Akademik Iyimserlik ve Psikolojik İyi Oluş Düzeylerinin İncelenmesi. Kahramanmaraş Sütçü Imam Üniversitesi Sosyal Bilimler Dergisi, 17 (1), 531-542. DOI: 10.33437/ksusbd.566586
} 


\title{
Investigating the Academic Optimism and Psychological Well-Being of Students of the Departments of Coaching and Sports Teaching
}

\begin{abstract}
This study was conducted with the aim of determining the levels of academic optimism and psychological well-being of coaching and sports teaching students based on some variables. The study included 280 volunteer participants including 160 from the department of physical education and sports teaching and 120 from the department of coaching. Study population is 385 students. The data in this study were collected, in addition to a personal information form, with academic optimism and psychological well-being scales in 2017-2018 academic year. According to the results, the mean academic optimism and psychological wellbeing levels of the sample were similar between the male and female participants. Higher psychological well-being scores were reported by the students of physical education in comparison to the students of coaching and the students who stayed at private dormitories (Mean=120,32) in comparison to those who stayed at state dormitories.
\end{abstract}

Keywords: Academic Optimism, Psychological Well-Being, Sport, Education.

\section{GİRIŞ}

İyimserlik ve kötümserlik, genellenmiş olumlu ve olumsuz sonuç beklentileridir (Scheier ve Carver, 1985: 219). İyimserlik kavramı, bir kişilik özelliği olarak içinde yaşanılan durum ve koşullardan bağımsız olarak, sürekli ve tutarlı biçimde kişinin yaşamında olumsuz sonuçlardan daha çok olumlu sonuçlar bekleme ve olumlu durumlarla karşılaşacağına inanma eğilimidir (Scheier ve Carver, 1992: 202). İyimserlik; beklenti, planlama, mantık ve eylemi içine alan bir kavramdır. Birey olumlu olaylarla karşılaşma olasılığ hakkında gerçekçi beklentiler içinde olmalıdır. Aynı gerçekçi beklentilerle olayı çözebilmek için mantıklı bir planlama yapmalıdır ve eyleme geçecek enerjiye ve güce sahip olup olumsuz durumla mücadele etmelidir. Bu durumda iyimserlik, hem bir duygu hem de öğrenilebilir, geliştirilebilir bir özellik olarak görülebilir (Gençoğlu, 2006: 10). Seligman'a (2006) göre de akademik iyimserliği de içine alan iyimserlik öğrenilebilir ve geliştirilebilir bir özelliktir.

Akademik iyimserlik bir öğretmenin, bilimsel bilgiye ve bilimsel öğrenmeye vurgu yaparak, aileler ve öğrencilerin süreç içerisinde işbirliği yapmaları gerektiğine inanarak, zorlukların üstesinden gelmede ve başarısızlık karşısında 
tepki vermede kendi kapasitesine inanarak, öğrencilerin akademik performansında değişiklik yapabileceği konusundaki pozitif inançlarıdır (Hoy vd., 2008). Akademik iyimserlik, öğretmen yeterliği, güven duygusu ve akademik vurgudan oluşan genel bir yapıdır (Smith ve Hoy, 2007). Ayrıca akademik iyimserlik ile öğrenci başarısı (Smit ve Hoy, 2007) ve okul başarısı (McGuigan ve Hoy, 2006) arasında pozitif yönlü bir ilişki bulunmaktadır. Öğretmenler derslerine iyimser olarak girerse öğrenciler buna pozitif yönde davranış sergileyerek karşılık verir ve sağlıklı öğrenme ortamı öğrencilerin başarısına pozitif katkı sağlar (Kurz, 2006).

Akademik iyimserlik, pozitif psikoloji üzerine yapılan araştırmalar sonucunda ortaya çıkmış bir yapıdır. Öğrencilerin başarısı için bir fark yaratmaktadır. Okulların akademik iyimserlikleri, kolektif yeterlik, okul güveni ve akademik önemin bilişsel, duyuşsal ve davranışsal yönlerini içeren kolektif bir yapıdır (Beard, vd., 2010; Hoy, 2012). Bu pozitif psikoloji yapısı olumsuzluklarla uğraşmak yerine yaşam değerlerine olumlu yaklaşma mücadelesini içerir ve sahip olunan pozitif inançlar psikolojik iyi olma haline zemin oluşturur.

Psikolojik iyi oluş ise yine pozitif psikoloji kapsamında değerlendirilmesi gereken, kişinin hayat endişesi ile bireysel ve sosyal ilgileri arasındaki dengeyi kurmak için çabalayacak gücünün olması olarak tanımlanmıştır. Ayrıca iyi oluşun yaşam doyumu ve duygu temelli değerlendirilmesinin bu işlevsel bakış açısını ihmal ettiğini öne sürmüştür. Psikolojik iyi oluş kavramı ile olumlu duygulanım, olumsuz duygulanım ve yaşam doyumunun basit bir birleşiminden çok, yaşam tutumlarından oluşan çok boyutlu bir yapının anlatılması gerektiği de belirtilmiştir (Ryff, 1989). Ayrıca psikolojik durumları pozitif olan bireylerin daha sağlıklı, mutlu, esnek, üretken ve başarılı olacakları ifade edilmiştir (Sezgin ve Erdoğan, 2015).

Ryan ve Deci (2001) iyi oluşu psikolojik ihtiyaçla açıklamıştır. Özerklik, yeterlik ve ilişki kurma temel psikolojik ihtiyaçlardır. Bunların karşılanma becerisi iyi oluşu açıklamaktadır. Bireyin psikolojik olarak kendilerini iyi hissetmeleri onların mutlu olmalarını sağlayacaktır. $\mathrm{Bu}$ da kişinin kendi gelişiminde ve kapasitesini olumlu yönde mesleğine yönlendirmesinde önemli rol oynacaktır.

Beden eğitimi öğretmenliği eğitim sisteminin önemli parçalarından olan bir meslektir. Bireyleri fiziksel, zihinsel, duygusal ve toplumsal yönleriyle bir bütün olarak yetiştirmek eğitimin sisteminin temel amacıdır. Eğitimdeki amacın gerçekleşmesi bireyin, zihinsel eğitimi yanında sosyal, fiziksel ve psikomotor eğitimi ile mümkündür. $\mathrm{Bu}$ anlamda beden eğitimi öğretmenleri öğrencilerin duyuşsal, bilişsel ve psiko-motor gelişimlerinden sorumludur. Bu nedenle beden 
eğitimi öğretmenlerinin mesleklerini başarılı bir şekilde sürdürmeleri çok önemli görülmektedir (Karaçam, 2016).

Başarı, önemli ölçüde kavramdan ne anlaşıldığına göre değişkenlik gösterir (Demirtaş ve Çınar, 2004). Dolayısıyla başarılı öğretmenden ne anlaşıldığ önemlidir (Sezgin ve Erdoğan, 2015). Alan yeterlilikleri, kişilik özellikleri, öğrenmeyi öğretme becerileri, sınıf yönetimi becerileri, planlama, değerlendirme becerileri, teknolojiyi kullanma, etkinlik alanları oluşturma, iletişim ve rehberlik becerileri gibi yeterliklere sahip öğretmenlerin tercih edilen öğretmen oldukları düşünülür (Şeker, Deniz ve Görgen, 2005). Beden eğitiminde, eğitimin diğer alanlarından farklı olarak "hareket öğrenme ve hareket yoluyla öğrenme" esas alınmaktadır (Tamer ve Pulur, 2001). Bu nedenle Milli Eğitim Bakanlığı (MEB) genel öğretmen niteliklerinin yanında başarılı beden eğitimi öğretmeninin niteliklerini şu şekilde belirtilmiştir: Spor yeteneği olan, göz-el ve ayaklarını eşgüdümle kullanabilen, bedence sağlam ve güçlü, spora karşı ilgili ve bu alanda başarılı, düşüncelerini başkalarına açık bir şekilde aktarabilen, iyi bir öğrenme ortamı sağlayabilen, dikkatli, işine özen gösteren, mesleğinin sorunlarıyla ilgilenen ve çözüm yolları bulmaya çalışan, insanlarla iyi iletişim kurabilen, sevecen, hoşgörülü, sabırl, öğrencilerin duygu ve düşüncelerini anlayabilen, kendini geliştirmeye istekli, coşkulu ve yaratıcı kimselerdir (Milli Eğitim Bakanlığı [MEB], 2019).

Bütün bu ifadelerden yola çıkarak beden eğitimi öğretmenleri ve antrenörlerin akademik iyimserlik ve psikolojik iyi oluş düzeylerinin yüksek olmasının, hem kendi mesleki yaşamlarında hem de kişisel yaşantılarındaki kaliteyi arttıracağ 1 söylenebilir. Dolayısıyla bu meslek grubunda yer alacakların akademik iyimserlik ve psikolojik iyi oluş düzeylerinin bilinmesi, konu ile ilgili sınırlı çalışmaların olmasından dolayı literature katkısı açısından önemli görülmektedir. $\mathrm{Bu}$ bağlamda beden eğitimi öğretmenlerinin başarı algılarını etkileyebilecek pozitif psikoloji değişkenlerinden akademik iyimserlik, psikolojik iyi oluş kavramları üzerinde durulmuştur.

$\mathrm{Bu}$ çalışma da beden eğitim ve spor öğretmenliği ile antrenörlük eğitimi bölümlerinde okuyan öğrencilerin akademik iyimserlik ve psikolojik iyi oluş düzeylerinin bazı değişkenlere göre nasıl şekillendiğini belirlemek amacı ile yapılmıştır.

\section{YÖNTEM}

Araştırma ilişkisel tarama modelinin kullanıldığı betimsel bir çalışmadır. 


\section{Çalışma Grubu}

Araştırmanın çalışma grubunu 2017-2018 eğitim ve öğretim yılında Kahramanmaraş Sütçü İmam Üniversitesi Beden Eğitimi ve Spor Yüksekokulu'nda okuyan ve çalışma evrenini oluşturan toplam 385 öğrenciden, Beden Eğitimi ve Spor Öğretmenliği (\%57,1) ile Antrenörlük Eğitimi bölümü öğrencilerinden (\% 42,9), yaşları 18 ile 25 arasında değişen, 154 erkek (\% 55) ve 126 bayan ( $\%$ 45) toplam 280 ögrenci oluşturmuştur.

\section{Veri Toplama Araçları}

Veri toplama aracı olarak kişisel bilgi formunun yanı sıra akademik iyimserlik ve psikolojik iyi oluş ölçeklerinden faydalanılmıştır. Akademik iyimserliklerini ölçmek amacıyla Hoy vd., (2006) tarafından geliştirilen akademik önemi ölçen ve toplam 11 maddeden oluşan akademik iyimserlik ölçeği kullanılmıştır. Ölçek orijinalinde 3 alt boyutlu olmasına rağmen Yıldız'ın (2011) ve Erdoğan (2013)'ın Türkçe geçerlik ve güvenirlik çalışmalarında tek boyutlu olarak ele alınmıştır. Çalışmada da ölçek tek boyutlu olarak değerlendirilmiştir. Ölçek 5'li likert derecelendirmeye sahip olup, hiç katılmıorum (1 puan) ve tamamen katıliyorum (5 puan) aralığında hesaplanmıştır Ölçeğin bütünü için Cronbach Alpha iç tutarlık katsayısı 0,85 olarak bulunmuştur. Psikolojik iyi oluşlarını ölçmek amacıyla Ryff (1989) tarafından geliştirilen 84 soruluk psikolojik iyi oluş ölçeğinin Akın vd., (2012) tarafindan geliştirilen 42 soruluk kısa formu kullanılmıştır. Ölçek 7'li likert derecelendirmeye sahip olup, kesinlikle katılmiyorum (1 puan) ve tamamen katılıyorum (7 puan) aralığında hesaplanmıştır. Ölçeğin bütünü için Cronbach Alpha iç tutarlık katsayısı 0,89 olarak bulunmuştur.

\section{Verilerin Analizi}

Araştırmadan elde edilen veriler SPSS 21 paket proğramı ile analiz edilmiştir. İstatistiksel analizler yapılmadan önce verilerin normal dağılıp dağılmadığ Kolmogorov smirnov ve Levene tesleri ile test edilmiştir. Parametrik verilere ait bağımsız değişkenlerin ikili karşılaştırmalarında t-test (independent sample), Non-parametrik verilere ait değişkenlerin ikili karşılaştırmaları Mann Whitney U testi, ikiden fazla grup karşılaştırmaları Kruscal Wallis testleri ile analiz edilmiştir. Bağımlı değişken durumundaki akademik iyimserlik ve psikolojik iyi oluş düzeyleri arasında ilişki olup olmadığı ise, Spearman correlation testi ile test edilmiştir. Çıkan sonuçların istatistiksel anlamlılık derecesi $\mathrm{p}<0.05$ olarak değerlendirilmeye alınmıştır.

\section{BULGULAR}

Araştırma grubundan elde edilen veriler tablolaştırılarak aşağıda sunulmuştur. 
Tablo 1. Araştırma Grubunun Cinsiyet Değişkenine Göre Analiz Sonuçları

\begin{tabular}{llccccc}
\hline Cinsiyet & & $\mathrm{N}$ & Mean & $\mathrm{SD}$ & $\mathrm{t}$ & $\mathrm{p}$ \\
\hline \multirow{2}{*}{ Akademik İyimserlik } & Bayan & 126 & 43,99 & 7,04 & \multirow{2}{*}{657} & \multirow{2}{*}{, 702} \\
\cline { 2 - 5 } Psikolojik İyi Oluş & Erkek & 154 & 44,01 & 8,56 & & \\
\hline & Bayan & 126 & 114,50 & 21,03 & \multirow{2}{*}{, 010} & \multirow{2}{*}{, 982} \\
\hline
\end{tabular}

Tablo 1'e göre araştırma grubunun cinsiyet değişkenine göre akademik iyimserlik $(\mathrm{t}=, 657 ; \mathrm{p}>0,05)$ ve psikolojik iyi oluş $(\mathrm{t}=, 010 ; \mathrm{p}>0,05)$ düzeyleri arasında istatistiksel olarak anlamlı fark olmadığı belirlenmiştir.

Tablo 2. Araştırma Grubunun Bölüm Değişkenine Göre Analiz Sonuçları

\begin{tabular}{|c|c|c|c|c|c|c|}
\hline Bölüm & & $\mathrm{N}$ & Mean & SD & $\mathrm{t}$ & $\mathrm{p}$ \\
\hline \multirow{2}{*}{$\begin{array}{l}\text { Akademik } \\
\text { iyimserlik } \\
\end{array}$} & Beden Eğt. Öğretmenliğ & 160 & 45,84 & 7,24 & \multirow{2}{*}{$-2,985$} & \multirow{2}{*}{,009* } \\
\hline & Antrenörlük Eğitimi & 120 & 38,32 & 9,44 & & \\
\hline \multirow{2}{*}{$\begin{array}{l}\text { Psikolojik iyi } \\
\text { oluş }\end{array}$} & Beden Eğt. Öğretmenliğ & 160 & 118,62 & 21,87 & \multirow{2}{*}{$-2,906$} & \multirow{2}{*}{,011* } \\
\hline & Antrenörlük Eğitimi & 120 & 111,47 & 20,10 & & \\
\hline
\end{tabular}

Tablo 2'ye göre araştırma grubunun bölüm değişkenine göre akademik iyimserlik düzeyi $(\mathrm{t}=2,985 ; \mathrm{p}<0,05)$ ve psikolojik iyi oluş $(\mathrm{t}=2,906 ; \mathrm{p}<0,05)$ düzeyleri arasında istatistiksel olarak anlamlı fark olduğu belirlenmiştir.

Tablo 3. Araştırma Grubunun Sınıf Değişkenine Göre Analiz Sonuçları

\begin{tabular}{|c|c|c|c|c|c|c|}
\hline Sinif & & $\mathrm{N}$ & Mean & SD & $\mathrm{X} 2$ & $\mathrm{p}$ \\
\hline \multirow{4}{*}{ Akademik iyimserlik } & 1.sinif & 80 & 44,18 & 8,24 & \multirow{4}{*}{3,120} & \multirow{4}{*}{,311 } \\
\hline & $2 . \sin 1 f$ & 82 & 40,28 & 10,11 & & \\
\hline & 3.sinif & 54 & 43,58 & 8,97 & & \\
\hline & $4 . \sin 1 \mathrm{f}$ & 64 & 45,28 & 5,48 & & \\
\hline \multirow{4}{*}{ Psikolojik iyi oluş } & $1 . \sin 1 f$ & 80 & 110,11 & 17,99 & \multirow{4}{*}{3,505} & \multirow{4}{*}{ 497 } \\
\hline & $2 . \sin 1 \mathrm{f}$ & 82 & 119,22 & 21,36 & & \\
\hline & 3. sinif & 54 & 112,88 & 24,46 & & \\
\hline & $\overline{4 . \sin 1 f}$ & 64 & 118,14 & 21,55 & & \\
\hline
\end{tabular}


Tablo 3'e göre araştırma grubunun sınıf değişkenine göre akademik iyimserlik $\left(X^{2}=3,120 ; p>0,05\right)$ ve psikolojik iyi oluş $\left(X^{2}=3,505 ; p>0,05\right)$ düzeyleri arasında

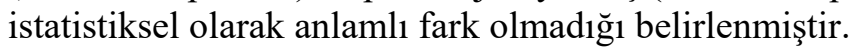

Tablo 4. Araştırma Grubunun Barındığı Yer Değişkenine Göre Analiz Sonuçları

\begin{tabular}{|c|c|c|c|c|c|c|c|}
\hline \multicolumn{2}{|c|}{ Barınd 1 ğ 1 yer } & $\mathrm{N}$ & Mean & SD & $\mathrm{X}^{2}$ & $\mathrm{p}$ & $\begin{array}{c}\text { Fark } \\
\text { U test }\end{array}$ \\
\hline \multirow{4}{*}{$\begin{array}{l}\text { Akademik } \\
\text { iyimserlik }\end{array}$} & 1.Devlet yurdu & 84 & 43,21 & 6,78 & \multirow{4}{*}{3,645} & \multirow{4}{*}{,502 } & \\
\hline & 2.Özel yurt & 42 & 46,98 & 5,48 & & & \\
\hline & 3.Ailemle & 104 & 43,25 & 8,44 & & & \\
\hline & 4.Diğer & 50 & 44,28 & 8,64 & & & \\
\hline \multirow{4}{*}{$\begin{array}{l}\text { Psikolojik } \\
\text { iyi oluş }\end{array}$} & 1.Devlet yurdu & 84 & 105,88 & 22,30 & \multirow{4}{*}{6,884} & \multirow{4}{*}{,023* } & \multirow{4}{*}{$2>1,3$} \\
\hline & 2.Özel yurt & 42 & 120,32 & 20,54 & & & \\
\hline & 3.Ailemle & 104 & 115,85 & 24,24 & & & \\
\hline & 4.Diğer & 50 & 119,41 & 23,33 & & & \\
\hline
\end{tabular}

Tablo 4'e göre araştırma grubunun sınıf değişkenine göre akademik iyimserlik düzeyinde fark bulunmazken $\left(X^{2}=3,645 ; p>0,05\right)$, psikolojik iyi oluş $\left(X^{2}=6,884\right.$; $\mathrm{p}<0,05)$ düzeyleri arasında istatistiksel olarak anlamlı fark olduğu belirlenmiştir.

Tablo 5. Araştırma Grubunun Akademik İyimserlik Ve Psikolojik İyi Oluş Düzeyleri Arasında Korelasyon Analiz Sonuçları

\begin{tabular}{llcc}
\hline Tanımlayıcı istatistikler & Akademik iyimserlik & Psikolojik iyi oluş \\
\hline \multirow{2}{*}{ Akademik iyimserlik } & Correlation & 1 & \\
\cline { 2 - 4 } & $\mathrm{p}$ & 280 & \\
\hline \multirow{2}{*}{ Psikolojik iyi oluş } & Correlation &, $474^{*}$ & 1 \\
\cline { 2 - 4 } & $\mathrm{p}$ &, 002 & 280 \\
\hline
\end{tabular}

Tablo 5'e göre araştırma grubunun akademik iyimserlik ve psikolojik iyi oluş düzeylerinin orta şiddette ve pozitif yönde doğrusal bir ilişki içerisinde olduğu görülmektedir $(\mathrm{r}=, 474 ; \mathrm{p}<0,05)$. Buna göre akademik iyimserlik düzeyi arttıkça psikolojik iyi oluş düzeyi de ona paralel olarak artış göstermektedir. 


\section{TARTIŞMA}

Araştırmada antrenörlük eğitimi ve beden eğitimi ve spor öğretmenliği bölümü öğrencilerinin akademik iyimserlik ve psikolojik iyi oluş düzeylerinin ele alınan değişkenlere göre nasıl şekillendiği belirlenmeye çalışılmıştır. Buna göre;

Araştırma grubunun cinsiyet ve sınıf değişkenine göre akademik iyimserlik ve psikolojik iyi oluş düzeylerinde herhangi bir fark gözlemlenmemiştir (Tablo 1-Tablo 3.). Eraslan vd. (2015), beden eğitimi ve spor yüksekokulu öğrencilerinin psikolojik iyi olma düzeylerini yaş, cinsiyet ve spor yapma değişkenleri göre incelediği çalışmada kadın katılımcıların psikolojik iyi olma düzeylerinin erkeklerden anlamlı şekilde daha yüksek olduğu sonucunu bulmuştur. Mevcut çalışmamızdan farklı olarak literatürde cinsiyet ile akademik iyimserlik düzeyleri arasında erkekler lehine anlamlı farklılıklara ulaşılan çalışmaların yanısıra (Çoban ve Demirtaş, 2011; Kiziroğlu, 2012), bazı çalışmalar cinsiyet açısından akademik iyimserlik düzeyleri arasında anlamlı bir fark olmadığını göstermektedir (Erdoğan, 2013; Çağlar, 2013; Yalçın, 2013). Motan (2002), kayg1 ve depresyonu ayrıştırma aracı olarak psikolojik dayanıklılığı kullandığ 1 çalışmasında, kişiliğin dolayısı ile psikolojik dayanıklılı̆̆ın birey üzerindeki etkisinin, stresli yaşam olaylarından daha fazla olduğunu belirtmiştir. Kişilik birey için kalıcı bir kavramken, stres veren olayların geçici olduğu düşünüldüğünden, etki oranları farklı olarak belirlenmiştir. Dolayısıyla araştırmada çıkan bu sonuç çalışmaya katılan grupların birbirinden farklı kişilik özelliklerine sahip olmasından kaynaklanması ile açılanabilir.

Araştırma grubunun bölüm değişkenine göre akademik iyimserlik ve psikolojik iyi oluş düzeylerinde fark gözlemlenmiştir. Beden eğitimi ve spor öğretmenliği bölümü öğrencilerinin akademik iyimserlik $(\bar{X}=45,84)$ ve psikolojik iyi oluş düzeyleri ( $\bar{X}=118,62$ ) daha yüksek bulunmuştur (Tablo 2.). Beden eğitimi ve spor öğretmenliği ve antrenörlük eğitimi bölümü öğrencileri sportif faaliyetler ile içe içe bir eğitim almaktadır. Bu sayede beden algısı, öz saygı gibi farklı kazanımlar onların psikolojik iyi oluş düzeylerine olumlu katkı sağlamış olabilir. Ancak öğretmenlik bölümü öğrencilerinin bölümlere yerleştirilirken akademik başarı puan ortalamalarının daha yüksek olduğu da bir gerçektir. Altıntaş vd. (2012) yaptıkları çalışmalarda spora aktif katılım düzeyi yüksek olan bireylerin psikolojik iyi oluş düzeyleri arasında anlamlı bir fark bulmuşlardır. Zekioğlu (2003) yaptığı çalışmada araştırmamızın sonucunu destekler şekilde spor yapan bireylerin beden algılarında spor yapmayanlara göre daha olumlu benlik algısına sahip olduklarını bulmuştur. Edwards vd. (2004) spor ve egzersiz yapan bireylerde psikolojik iyi oluş ve fiziksel öz sayg1 üzerine yapılan çalışmanın bulguları ile çalışmamızın bulguları paralellik göstermektedir. 
Araştırma grubunun barındığı yer değişkenine göre psikolojik iyi oluş düzeylerinde özel yurtta kalanlar lehine fark gözlemlenmiştir $(p<0,05)$. Buna göre özel yurtta kalanların devlet yurdu ve ailesi ile kalanlara göre kendilerini daha iyi hissettikleri söylenebilir. Ryff (1989) psikolojik iyi oluş modelinin teorik yapısını ve ölçümünü açıkladığı çalışmasında, psikolojik iyi oluşun, yaşam doyumuna bağlı olarak kişilerin sağlık durumları ve mali durumlarının önemli olduğunu ifade etmiştir. Ayrıca iyi oluşu sadece mutlu olmaktan ziyade kişinin gerçek potansiyelini gerçekleştirme çabası olarak nitelendirmiştir. Bu bakış açısına göre mutluluk iyi bir yaşamın sonucu olabilir. Bahsedilen iyi yaşam, psikolojik iyi oluş faktörleri, diğerleriyle olumlu ilişkiler, özerklik, çevre hâkimiyeti, yaşam amacı, kişisel gelişim ve kendini kabulü yansıtmaktadır (Karaçam, 2016). Rile vd. (2015) akademik personelin psikolojik iyi oluş ve akademik iyimserlikleri üzerine yaptıkları çalışmada, psikolojik iyi oluş ile akademik iyimserlik arasında yüksek düzeyde anlamlı bir ilişkinin olduğunu bulmuşlardır. Mevcut çalışmada da araştırma grubunun akademik iyimserlik ve psikolojik iyi oluş düzeylerinin pozitif yönde doğrusal ve orta düzeyde $(r=, 474)$ anlamlı bir ilişki içerisinde olduğu bulunmuştur. Buna göre akademik iyimserlik düzeyi arttıkça psikolojik iyi oluş düzeyi de ona paralel olarak artış göstermektedir.

\section{SONUÇ}

Araştırma sonuçlarına göre; çalışma grubunun cinsiyet değişkenine göre bayan ve erkek öğrencilerin akademik iyimserlik ve psikolojik iyi oluş düzeylerine ait puan ortalamaları arasında benzerlik olduğu görülmüştür. Beden eğitimi öğretmenliği bölümü öğrencilerinin antrenörlük eğitimi bölümü öğrencilerine göre, özel yurtta kalanların devlet yurdunda kalanlara göre psikolojik iyi oluş düzeyleri daha yüksektir. Ayrıca araştırmanın bulguları beden eğitimi öğretmenliği ve antrenörlük eğitimi bölümü öğrencilerinin akademik iyimserlik ve psikolojik iyi oluş düzeylerinin birbiriyle pozitif yönlü, orta düzeyde $(\mathrm{r}=, 474 ; \mathrm{p}<0,05)$ ve anlamlı bir ilişki içerisinde olduğunu ortaya koymaktadır.

Araştırma sınırlı bir örneklem grubu üzerinde yürütülmüştür. Daha geniş ve farklı gruplar üzerinde çalışmaların yapılması konunun literatüre katkı sağlaması açısından faydalı olacaktır.

\section{KAYNAKLAR}

Altıntaş, Atahan; Aşçı, Fatma Hülya; İşler, Ayşe Kin; Karahan, Bengü Güven; Kelecek, Selen; Özkan, Ali; Yılmaz, Atakan ve Kara, Feyza Meryem (2012), "The role of physical activity and body massindex in psychological well-being of adolescents", 12. International Sport Sciences Congress, 12-14 Aralık, Denizli. 
Beard, Karen Stansberry; Hoy, Wayne K ve Hoy, Anita Woolfolk (2010), "Academic optimism of individual teachers: Confirming a new construct”, Teaching and Teacher Education, 26, ss. 1136-1144.

Çağlar, Çağlar (2013), “Okulların akademik iyimserlik düzeyinin öğretmenlerin örgütsel bağlılı̆g üzerindeki etkisi”, Mersin Üniversitesi Eğitim Fakültesi Dergisi, 9(1), ss. 260-273.

Çoban, Duygu ve Demirtaş, Hasan (2011), "Okulların akademik iyimserlik düzeyi ile öğretmenlerin örgütsel bağlılı̆̆ı arasındaki ilişki”, Kuram ve Uygulamada Eğitim Yönetimi Dergisi, 17(3), ss. 317-348.

Demirtaş, Hasan ve Çınar, İkram (2004), “Yönetici, öğretmen, veli ve öğrencilerin başarı algısı ve eğitime ilişkin görüşleri”, 13. Ulusal Eğitim Bilimleri Kurultayı, 6-9 Temmuz, Malatya.

Edwards, David J; Edwards, Stephen D ve Basson, Clive J. (2004), "Psychological well being and physical self-esteem in sport and exercise”, International Journal of Mental Health Promotion, 6(1), ss. 2532.

Eraslan, Meriç; Çalışkan, Gökhan ve Baş, Mustafa (2015), "Beden eğitimi ve spor yüksekokulu öğrencilerinin yaş, cinsiyet ve spor yapma durumlarma göre incelenmesi”, of International Multidisciplinary Academic Researches, 2(1), ss. 48-54.

Erdoğan, Onur (2013), “ïlköğretim Öğretmenlerinin Öz Yeterlilik ve Başarı Algılarında Yordayıı Olarak Akademik İyimserlik, Umut ve Mesleki Haz”, Yayımlanmamış Yüksek lisans tezi, Gazi Üniversitesi, Eğitim Bilimleri Enstitüsü, Ankara.

Gençoğlu, Cem (2006), "Üniversite öğrencilerinin iyimserlik düzeyleri ile kişilik özellikleri arasındaki ilişkinin İncelenmesi”, Yayımlanmamış Yüksek Lisans Tezi, Ondokuz Mayıs Üniversitesi Sosyal Bilimler Enstitüsü, Samsun.

Hoy, Anita Woolfolk; Hoy, Wayne K ve Kurz, Nan M. (2008), “Teacher's academic optimism: The development and test of a new construct", Teaching and Teacher Education, 24, ss. 821-835.

Hoy, Wayne K. (2012), "School characteristics that make a difference for the achievement of all students: A 40-year academic odyssey", Journal of Educational Administration, 50, ss. 76-97. 
Hoy, Wayne K; Tarter, John C ve Hoy, Anita Woolfolk (2006), “Academic optimism of schools: A force for student achievement”, American Educational Research Journal, 43(3), ss. 425-446.

Karaçam, Aydın (2016), "Beden Eğitimi Öğretmenlerinin Başarı Algılarında Yordayıcı Olarak Akademik İyimserlik, Psikolojik İyi Oluş ve Fiziksel Saygı”, Yayımlanmamış Doktora Tezi, Gazi Üniversitesi Eğitim Bilimleri Enstitüsü, Ankara.

Kiziroğlu, Merve (2012), "Sınıf öğretmenlerinin sosyo demografik özelliklerine göre umutsuzluk düzeyleri”, Yayımlanmamış Yüksek Lisans Tezi, Atatürk Üniversitesi, Erzurum.

Kurz, Nan M. (2006), “The relationship between teachers' sense of academic optimism and commitment to the profession”, Unpublished doctoral dissertation, University of Ohio State, USA.

McGuigan, Leigh ve Hoy, Wayne K. (2006), “Principal leadership: Creating a culture of academic optimism to improve achievement for all students”, Leadership and Policy in Schools, 5(3), ss. 203-229.

Milli Eğitim Bakanlığı (2019), “Beden eğitimi öğretmenleri özel alan yeterlilikleri”,

http://oygm.meb.gov.tr/meb_iys_dosyalar/2017_11/06160702_11-

YYretmen_Yeterlikleri_KitabY_beden_eYitimi_YYretmeni_Yzel_alan_ yeterlikleri_ilkYYretim_parYa_14.pdf sayfasından erişilmiştir.

Motan, İrem (2002), "Kaygı ve depresyonu ayrıştırmak: Dayanıklılık", Yayımlanmamış Yüksek Lisans Tezi, Orta Doğu Teknik Üniversitesi, Sosyal Bilimler Enstitüsü, Psikoloji Bölümü, Ankara.

Rile, Luis Guanzon; Tan, Nemia Ladesma; Salazar, Neda June ve Perez, Ann Gloghienette Orais (2015), “Expat University Professors' State of Psychological Well-being and Academic Optimism towards University Task in UAE. Systemics”, Cybernetics and Informatics, 13(3), ss. 28-33.

Ryan, Richard M. ve Deci, Edward L. (2001), “On happiness and human potentials: A review of research on hedonic and eudaimonic wellbeing”, Annual review of psychology, 52(1), ss. 141-166.

Ryff, Carol D. (1989), "Happiness is everything, or is it? Explorations on the meaning of psychological well-being", Journal of personality and social psychology, 57(6), ss. 1069-1081. 
Scheier, Michael F ve Carver, Charles S. (1992), "Effect of optimism on psychological and physical well-being: Thorical over view and emprical update”, Cognitive Theraphy and Research, 16(2), ss. 201-228.

Scheier, Michael F ve Carver, Charles S. (1985), “Optimism, coping and health: Assessment and implications of generalized outcome expectancies”, Health Psychology, 4, ss. 219-247.

Seligman, Martin (2006), Learned optimism. How to change your mind and your life (2nd ed.), Pocket Books, New York.

Sezgin, Ferudun ve Erdogan, Onur (2015), “Academic optimism, hope and zest for work as predictors of teacher self-efficacy and perceived success", Educational Sciences: Theory \& Practice, 15(1), ss. 7-19.

Smith, Page A ve Hoy, Wayne K. (2007), “Academic optimism and student achievement in urban elementary schools", Journal of Educational Administration, 45(5), ss. 556-568.

Şeker, Hasan; Deniz, Sabahattin ve Görgen, İzzet (2005), “Tezsiz yüksek lisans öğretmen adaylarının öğretmenlik yeterlikleri üzerine değerlendirmeleri”, Kuram ve Uygulamada Eğitim Yönetimi, 42, ss. 237253.

Tamer, Kemal ve Pulur, Atilla (2001), Beden eğitimi ve sporda öğretim yöntemleri. Ada Yayınları, Ankara.

Yalçın, Simge (2013), “ïlköğretim okulu öğretmenlerinin mesleki tükenmişlik düzeyleri ile stres, psikolojik dayanıklılık ve akademik iyimserlik arasındaki ilişki”, Yayımlanmamış Yüksek Lisans Tezi, Gazi Üniversitesi, Ankara.

Yıldız, Gülizar (2011), “Akademik iyimserlik ölçeğinin Türkçeye uyarlanabilirliğinin incelenmesi”, Yayımlanmamış Yüksek lisans tezi, Gazi Üniversitesi, Ankara.

Zekioğlu, Aylin (2003), "Spor yapan ve sedanter yaşayanlarda çok yönlü beden-self ilişkisi”, Yayımlanmamış Yüksek Lisans Tezi, Celal Bayar Üniversitesi Sağlık Bilimleri Enstitüsü, Manisa. 